\title{
Human pancreatic Beta-cell glucokinase: cDNA sequence and localization of the polymorphic gene to chromosome 7, band $\mathbf{p} 13$
}

\author{
S. Nishi ${ }^{1,3}$, M.Stoffel ${ }^{1}$, K.Xiang ${ }^{1}$, T.B.Shows ${ }^{2}$, G. I. Bell ${ }^{1}$ and J. Takeda ${ }^{1}$ \\ ${ }^{1}$ Howard Hughes Medical Institute, and Departments of Biochemistry and Molecular Biology, and Medicine, University of Chicago, \\ Chicago, Illinois, ${ }^{2}$ Department of Human Genetics, Roswell Park Memorial Institute, New York State Department of Health, Buffalo, \\ New York, USA, and ${ }^{3}$ Second Division of Internal Medicine, Hamamatsu University School of Medicine, Hamamatsu, Shizuoka, Japan
}

\begin{abstract}
Summary. The glucose phosphorylating enzyme glucokinase plays an important role in the regulation of glucose homeostasis. Studies in rodents indicate that pancreatic Beta cells and hepatocytes express different isoforms of this protein as a consequence of the presence of tissue-specific promoters and exon 1 sequences which are spliced to a shared group of nine exons which encode most of the mRNA and protein. Here, we report the isolation and characterization of cDNA clones encoding human Beta-cell glucokinase. The sequence of human Beta-cell glucokinase shows 97\% amino acid identity with that of the cognate rat protein. We also mapped the human glucokinase gene to the short arm of chromosome 7 by analysing its segregation in a panel of reduced human-
\end{abstract}

mouse somatic cell hybrids. In situ hybridization to metaphase chromosomes confirmed the localization of the human glucokinase gene to chromosome 7 and indicated that it was in band $\mathrm{p} 13$. A microsatellite DNA polymorphism that can be typed using the polymerase chain reaction was identified upstream of exon $1 \mathrm{a}$, the Beta-cell specific first exon. The glucokinase cDNA clone and highly informative DNA polymorphism will be useful for examining the role of this gene in the pathogenesis of diabetes mellitus.

Key words: Glucokinase, polymerase chain reaction, microsatellite DNA polymorphism.
Glucokinase (ATP: D-hexose 6-phosphotransferase, EC 2.7.1.1) is expressed by hepatocytes and pancreatic Beta cells and plays a key role in the regulation of glucose homeostasis $[1,2]$. In the hepatocyte, the phosphorylation of glucose by glucokinase facilitates the uptake and metabolism of glucose by maintaining a gradient for glucose transport into these cells. In Beta cells, glucokinase is believed to comprise part of the glucose sensing mechanism which regulates insulin secretion. In the rat, glucokinase is encoded by a single-copy gene that has 11 exons $[1,3,4]$. The glucokinase transcripts present in the liver and Beta-cell share sequences encoded by the last nine exons. The sequences of the liver and Beta-cell glucokinase mRNA differ at their 5'-ends because the glucokinase gene has two promoters, one of which functions in the Beta cell and the other which is active in liver. As a consequence, the sequences of the $5^{\prime}$-untranslated regions of the two transcripts differ. In addition, since translation is initiated within the tissue-specific first exon, the sequence of amino acids $1-15$ of the liver and Beta-cell isoforms are different. The presence of tissue-specific alternative promoters allows the glucokinase gene to be differentially regulated in these two tissues.
Because of the important role played by glucokinase in the regulation of insulin secretion and the uptake of glucose by the liver, it has been implicated as a candidate gene whose genetic variation or altered regulation could contribute to the development of Type 2 (non-insulin-dependent) diabetes mellitus. Tanizawa et al. [5] have recently described the isolation and characterization of cDNA clones encoding the hepatic isoform of human glucokinase. In this report, we present the sequence of the human Beta-cell isoform. In addition, we have mapped the human glucokinase gene (GCK) to chromosome 7 , band p13, and identified a microsatellite DNA polymorphism that will facilitate genetic studies of its role in the development of Type 2 diabetes.

\section{Materials and methods}

\section{General methods}

Standard methods were carried out as described in Sambrook et al. [6] and as described previously [7]. DNA sequencing was done by the dideoxynucleotide chain-termination procedure after subcloning appropriate DNA fragments into M13mp18 or M13mp19. The sequence was confirmed on both strands. 
Met Glu Ala Ala Lys Lys Glu Lys Val Giu Gln Ile Leu Ala Glu Phe Gln Leu Gln Glu Glu asp Leu Lys Lys Val Met Arg Arg Met ATG GAG GCC GCC AAG AAG GAG AAG GTA GAG CAG ATC CTG GCA GAG TIC CAG CTG CAG GAG GAG GAC CTG AAG AAG GTG ATG AGA CGG ATG GGC ICA GAA GTC GGG GAC TTC CTC TCC CTG GAC CTG GGT GGC ACT AAC TTC AGG GTG ATG CTG GTG AAG GTG GGA GAA GGT GAG GAG GGG CAG TGG AGC GTG AAG ACC AAA CAC CAG ATG TAC TCC ATC CCC GAG GAC GCC ATG ACC GGC ACT GCT GAG ATG CTC TPTC GAC TAC ATC TCT GAG TGC ATC TCC GAC TTC CTG GAC AAG CAT CAG ATG AAA CAC AAG AAG CTG CCC CTG GGC TTC ACC TTC TCC TTT CCT GTG AGG CAC GAA

Leu 160 170

\section{Ile}

Asp Ile Asp Lys Gly Ile Leu Leu Asn Trp Thr Lys Gly Ile Lys Ala Ser Gly Ala Glu Gly Asn Asn Val Val Gly Lel Leu Arg Asp GAC ATC GAT AAG GGC ATC CTT CTC AAC TGG ACC AAG GGC ATC AAG GCC TCA GGA GCA GAA GGG AAC AAT GTC GTG GGG CTT CTG CGA GAC 190 200 210 Ala Ile Lys Arg Arg Gly Asp phe Glu Met Asp Val Val Ala Met Val Asn Asp Thr Val Ala Thr Met Ile Ser Cys Tyr Tyr Glu Asp GCT ATC AAA CGG AGA GGG GAC TTT GAA ATG GAT GTG GTG GCA ATG GTG AAT GAC ACG GTG GCC ACG ATG ATC TCC TGC TAC TAC GAA GAC Arg Gis Cys Glu Val Gly Met Ile val Gly Thr Gly Cys Asn Ala Cys Tyr Met Glu Glu Met Gln Asn Val Glu Leu Val Glu Gly Asp 230 240 CAT CAG TGC GAG GTC GGC ATG ATC GTG GGC ACG GGC TGC AAT GCC TGC TAC ATG GAG GAG ATG CAG AAT GTG GAG CTG GTG GAG GGG GAC $25020260 \quad 270 \quad$ Met Glu Gly Arg Met Cys val Asn Thr Giu Trp Gly Ala phe Gly Asp Ser Gly GIu Leu Asp Glu Phe Leu Leu Glu Tyx Asp Arg Leu Val GAG GGC CGC ATG TGC GTC AAT ACC GAG TGG GGC GCC TTC GGG GAC TCC GGC GAG CTG GAC GAG TTC CTG CTG GAG TAT GAC CGC CTG GTG $280 \quad 290 \quad$ Ile 300

Asp Glu Ser Ser Ala Asn Pro Gly Gln Gln Leu Tyr Glu Lys Leu Ile Gly Gly Lys Tyr Met Gly Glu Leu Val Arg Leu Val Leu Leu GAC GAG AGC TCT GCA AAC CCC GGT CAG CAG CTG TAT GAG AAG CTC ATA GGT GGC AAG TAC ATG GGC GAG CTG GTG CGG CTI GTG CTS CTC Lys $310 \quad 320 \quad 330$ Arg Leu Val Asp Glu Asn Leu Leu Phe His Giy Glu Ala Ser Glu Gln Leu Arg Thr Arg Gly Ala Phe Glu Thr Arg Phe Val Ser Gln AGG CTC GTG GAC GAA AAC CTG CTC TTC CAC GGG GAG GCC TCC GAG CAG CTG CGC ACA CGC GGA GCC TTC GAG ACG CGC TTC GTG TCG CAG

$$
340 \text { Ser His } 350 \quad 360 \mathrm{Val} \text { Asn }
$$

Val Glu Ser Asp Thr Gly Asp Arg Lys Gin Ile Tyr Asn Ile Leu Ser Thr Leu Gly Leu Arg Pro Ser Thr Thx Asp Cys Asp Ile Val GTG GAG AGC GAC ACG GGC GAC CGC AAG CAG ATC TAC AAC ATC CTG AGC ACG CTG GGG CTG CGA CCC TCG ACC ACC GAC TGC GAC ATC GTG

$370 \quad 380 \quad 390$

Arg Arg Ala Cys Glu Ser Val Ser Thr Arg Ala Ala His Met Cys Ser Ala Gly tel Ala Gly Val Ile Asn Arg Met Arg Glu Ser Arg CGC CGC GCC TGC GAG AGC GTG TCT ACG CGC GCT GCG CAC ATG TGC TCG GCG GGG CTG GCG GGC GTC ATC AAC CGC ATG CGC GAG AGC CGC 400 410 420 Ser Glu Asp Val Met Arg Ile Thr Val Gly Val Asp Gly Ser Val Tyr Lys Leu His Pro Ser Phe Lys Glu Arg Phe His Ala Ser Vai AGC GAG GAC GTA ATG CGC ATC ACT GTG GGC GTG GAT GGC TCC GTG TAC AAG CTG CAC CCC AGC TTC AAG GAG CGG TTC CAT GCC AGC GTG Arg Arg Leu Thr Pro Ser Cys Glu Ile Thr Phe Ile Glu Ser Glu Glu Gly Ser Gly Arg Gly Ala Ala Leu Val Ser Ala Val Ala Cys Arg Arg Leu Thr Pro Ser Cys Glu Ile Thr Phe Ile Glu Ser Giu Glu Giy Ser Giy Arg Gly Ala Ala Leu val Ser Ala val Ala Cys 460
Lys Lys Ala Cys Met Leu Gly Gln oP

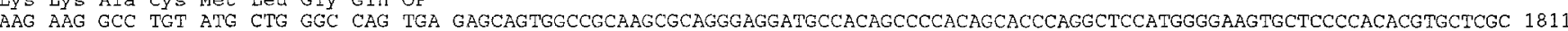
AGCCTGGCGGGGCAGGAGGCCTGGCCTTGTCAGGACCCAGGCCGCCTGCCATACCGCTGGGGAACAGAGCGGGCCTCTTCCCTCAGTTTTTCGGTGGGACAGCCCCAGGGCCCTAACGGG 1931 GGTGCGGCAGGAGCAGGAACAGAGACTCTGGAAGCCCCCCACCTTTCTCGCTGGAATCAATTTCCCAGAAGGGAGTTGCTCACTCAGGACTTTGATGCATTTCCACACTGTCAGAGCTGT 2051 TGGCCTCGCCTGGGCCCAGGCTCTGGGAAGGGGTGCCCTCTGGATCCTGCTGTGGCCTCACTTCCCTGGGAACTCATCCTGTGTGGGGAGGCAGCTCCAACAGCTTGACCAGACCTAGAC 2171 CTGGGCCAAAAGGGCAGCCAGGGGCTGCTCATCACCCAGTCCTGGCCATTTTCTTGCCTGAGGCTCAAGAGGCCCAGGGAGCAATGGGAGGGGGCTCCATGGAGGAGGTGTCCCAAGCTT 229 1 TGAATACCCCCAGAGACCTTTTCTCTCCCATACCATCACTGAGTGGCTTGTGATTCTGGGATGGACCCTCGCAGCAGGTGCAAGAGACAGAGCCCCCAAGCCTCTGCCCCAAGGGGCCCA 2411 CAAAGGGGAGAGGGCCAGCCCPACATCTTCAGCTCCCATAGCGCTGGCTCAGGAAGAAACCCCAAGCAGCATICAGCACACCCCAAGGGACAACCCCATCATATGACATGCCACCCTCT 2531 CCATGCCCAACCTAAGATTGTGTGGGTTTTTTAATTAAAAATGTTAAAAGTTTTAAAAAAAAAAAAAAAAAAAAA

Fig.1. Composite nucleotide sequence of human Beta-cell glucokinase cDNA and predicted amino acid sequence of the protein. The sequence encoded by the Beta-cell-specific exon 1a is shown in bold-face type. The number of the nucleotide at the end of each line is noted. The sequence was obtained from the following clones: hGK-p5, nucleotides 1-393; hGK3.1, nucleotides 372-831; and hGK12-1, nucleotides 771-2606. The corresponding amino acid residue of rat Beta-cell glucokinase $[4,14]$ is indicated above that of the human sequence at those sites at which the sequences differ. There are three differences between the cDNA sequence presented here and the sequence of human liver glucokinase [15] in the region in which these two sequences overlap-Codon 107 is $\mathrm{ATG}$ (Met) here, in the human glucokinase gene (unpublished) and in the rat glucokinase cDNA sequence [14], and ACG (Thr) in Matsutani et al. [15]; and there are two differences in the 3'-untranslated region (underlined) which are $\mathrm{G}$ and $\mathrm{C}$ in our sequence and $\mathrm{GG}$ and $\mathrm{CC}$, respectively, in Reference 15 . We show the sequence of codon 74 as being TTC (Phe) which is also the sequence in Reference 15 and in the gene (unpublished). However, in two independent polymerase chain reaction products that were obtained from this region it was TCC (Ser). We assume that this difference is a consequence of misincorporation by either reverse transcriptase or Taq DNA polymerase. It is unknown if the sequence differences noted above represent polymorphisms in the human glucokinase gene 


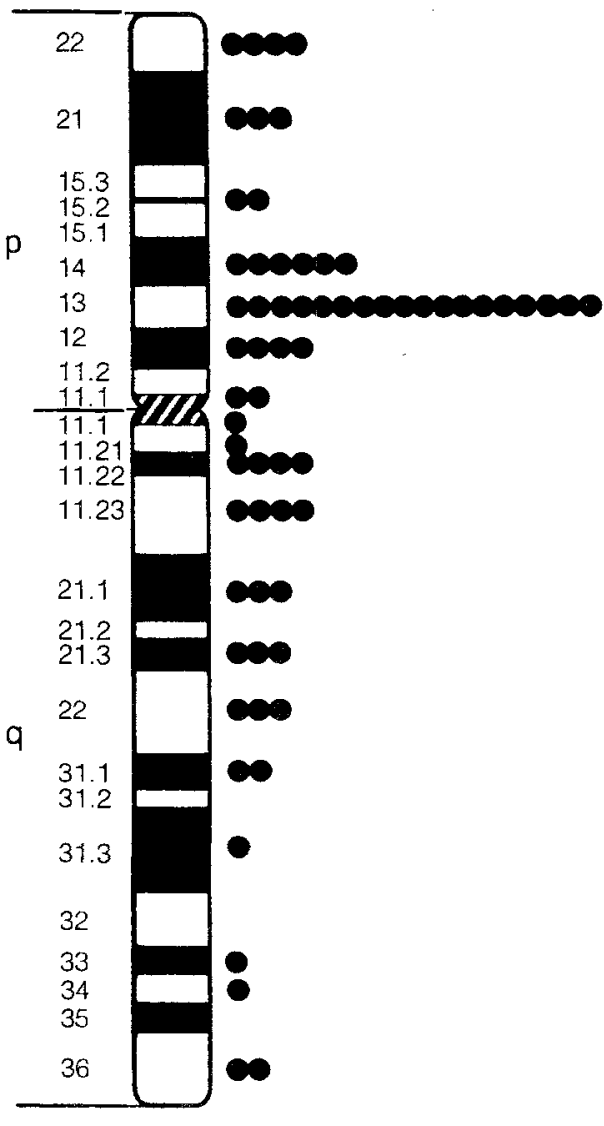

7

Fig. 2. Ideogram of human chromosome 7 showing silver grain distribution after hybridization with phGK12-1. One hundred metaphase spreads were examined. Of the total number of grains, $27.1 \%$ (65 of 240 ) were on chromosome 7 , and of these, $36.9 \%$ ( 24 of 65 ) were at $7 \mathrm{p} 13 \rightarrow \mathrm{p} 14$. Eighteen percent of metaphase spreads examined showed a silver grain at $7 \mathrm{p} 13 \rightarrow \mathrm{p} 14$

\section{Isolation of human glucokinase cDNA clones}

A human liver cDNA library was screened using low-stringency hybridization conditions [8] (hybridization conditions $-5 \times$ SSC, $25 \%$ formamide, $2 \times$ Denhardt's solution, $20 \mathrm{mmol} / \mathrm{l}$ sodium phosphate buffer, $\mathrm{pH} 6.5,0.1 \%$ sodium dodecyl sulphate, $100 \mu \mathrm{g} / \mathrm{ml}$ of sonicated and denatured salmon testes DNA, 10\% dextran sulphate, and $1 \times 10^{5} \mathrm{cpm} / \mathrm{ml}$ of probe at $37^{\circ} \mathrm{C}$ for $16-20 \mathrm{~h}$; washing conditions $-2 \times \mathrm{SSC}$ and $0.1 \%$ sodium dodecyl sulphate, for $1 \mathrm{~h}$ each at room temperature and then at $40^{\circ} \mathrm{C}$ ) with a ${ }^{32} \mathrm{P}$-labelled 3248 base pair (bp) EcoRI fragment of the human hexokinase I cDNA clone, $\lambda \mathrm{hHEX}$ 15 [7], which codes for amino acids $92-917$ and the $3^{\prime}$-untranslated region of the mRNA. The cDNA clone $\lambda$ hGK12-1 was obtained using this procedure. The remainder of the CDNA was obtained by reverse transcription-polymerase chain reaction (PCR) amplification of human insulinoma mRNA using specific primers [rGK-13 (sense primer) 5'-GTCGAGCAGATCCTGGCAGAG-3' and ohGK-2r (antisense primer) 5'-TGGTCCAGTTGAGAAGGAAG-3'; the sequence of rGK-13 was based on the sequence of rat glucokinase $\mathrm{mRNA}$ ] which gave cDNA clone - hGK3.1, and by the rapid amplification of cDNA ends (RACE) procedure [9] using human insulinoma mRNA and the specific primer (antisense) 5'-CTCTGCCAGGATCTGCTCTAC-3' which generated a cDNA clone, hGK-p5, containing the 5'-end of human Beta-cell glucokinase mRNA. At least two PCR and RACE products obtained from each amplification were sequenced to control for errors that might be introduced in the amplification by Taq DNA polymerase. A
cDNA encoding the human Beta-cell isoform of glucokinase, designated pGEM-hGK20 (vector-pGEM4Z) was generated using the three clones described above.

\section{Gene mapping}

The chromosomal location of human GCK was determined by hybridization of ${ }^{32} \mathrm{P}$-labelled phGK12-1 (the insert of $\lambda \mathrm{GK} 12-1$ subcloned into pBR327) to Southern blots of EcoRI-digested DNA from 36 different reduced human-mouse somatic cell hybrid cell lines [10] as described previously [11]. The regional localization of GCK was determined by in situ hybridization of ${ }^{3} \mathrm{H}$-labelled phGK12-1 to normal human prometaphase chromosomes as described by Nakai et al. [12].

\section{Isolation of the human GCK gene and identification of a microsatellite DNA polymorphism}

The human GCK gene was isolated from a genomic library (946203, Stratagene, La Jolla, Calif., USA) by hybridization with the insert from the cDNA clone $\mathrm{GGEM}-\mathrm{h}$ GK 20 . Five clones $[\lambda \mathrm{hGK}-1,-2,-4,-5$ and -7] were isolated; these clones contain all the exons of the human GCK gene. The clones containing CA-dinucleotide repeats were identified by hybridization with nick-translated ${ }^{32} \mathrm{P}$-labelled poly (dA-dC)-poly (dG-dT) (Pharmacia LKB Biotechnology, Piscataway, NJ, USA) [13] (hybridization conditions $-0.5 \mathrm{~mol} / \mathrm{l}$ sodium phosphate buffer, $\mathrm{pH} 7.0,7 \%$ sodium dodecyl sulphate, $1 \%$ bovine serum albumin, and $1 \times 10^{6} \mathrm{cpm} / \mathrm{ml}$ of probe at $42^{\circ} \mathrm{C}$ for $16-20 \mathrm{~h}$; washing conditions $-1 \times$ SSC and $1 \%$ sodium dodecyl sulphate, for $1 \mathrm{~h}$ each at room temperature and then at $50^{\circ} \mathrm{C}$ ). A $3.0 \mathrm{~kb}$ Hind III fragment from $\lambda$ hGK-7 was isolated, digested with Sau3A I, and ligated into BamHI-digested M13mp19. The inserts in M13 clones hybridizing with ${ }^{32} \mathrm{P}$-labelled poly (dA-dC)-poly (dG-dT) were sequenced.

\section{Amplification of the microsatellite DNA polymorphism}

Two primers (hGK-CA-1, 5'-AACAGATACGCTTCATCCTG-3'; and $\mathrm{hGK}$-CA-2, $5^{\prime}$-TGTCTGCAACTTACTC TTAC-3') were used to amplify a $127-143$ bp TC and AC repeat-rich region upstream of the Beta-cell specific exon, exon $1 \mathrm{a}$, of human GCK. The PCR was performed using ${ }^{32} \mathrm{P}$-labelled hGK-CA-1 and unlabelled hGKCA-2. DNA was initially denatured at $94^{\circ} \mathrm{C}$ for $6 \mathrm{~min}$, followed by 30 cycles of denaturation at $94^{\circ} \mathrm{C}$ for $1 \mathrm{~min}$, annealing at $60^{\circ} \mathrm{C}$ for $2 \mathrm{~min}$, extension at $72^{\circ} \mathrm{C}$ for $2 \mathrm{~min}$ and a final extension step of $10 \mathrm{~min}$. The PCR products were analysed on a $5 \%$ denaturing polyacrylamide gel. The PCR reactions were carried out in a volume of $25 \mu \mathrm{l}$ containing $50 \mathrm{mmol} / \mathrm{l} \mathrm{KCl}, 10 \mathrm{mmol} / \mathrm{l}$ Tris- $\mathrm{HCl}$ (pH 8.3), $1.5 \mathrm{mmol} / \mathrm{MgCl} \mathrm{Mg}_{2}, 100 \mu \mathrm{g} / \mathrm{ml}$ gelatin, $200 \mu \mathrm{mol} / \mathrm{l}$ each of dATP, dGTP, dCTP, and dTTP; and $0.1 \mu \mathrm{g}$ of DNA, 10 pmol of each primer, and $1.5 \mathrm{U}$ of Taq polymerase (Perkin Elmer Cetus, Norwalk, Conn., USA).

\section{Results}

Sequence of human Beta-cell glucokinase cDNA and protein

Human glucokinase cDNA clones were isolated from a liver cDNA library by low-stringency cross-hybridization with a human hexokinase I cDNA probe. The sequence of the insert in one of these clones, now termed $\lambda$ hGK12-1, did not correspond to hexokinase I. With the publication 
$\mathrm{hGK}-\mathrm{CA}-1$ TTGCACTCCTGCCTGGGCAACAGAGCAAGACCCTGTCACAAAGCAAAACAAACAAACAGATACGCTTCAT AACGTGAGGACGGACCCGTTGTCTCGTTCTGGGACAGTGTTTCGTTTTGTTTGTTTGTCTATGCGAAGTA

CCTGATTCCTGTATTTGCTTTATCATTCTCTTTCTCTCTGTCTCTCTCTCTCTCTGTCTCTCTCTCTCTC GGACTAAGGACATAAACGAAATAGTAAGAGAAAGAGAGACAGAGAGAGAGAGAGACAGAGAGAGAGAGAG
TCACACACACACACACACACACACACACACCCTGTAAGAGTAAGTTGCAGACACAATGTCCCTTTACTTC hGK-CA-2

TAAATTCTTCTMGTGTATATTTCCTATAAACAAGACTCTCTTATATACCATGGCACAGTGATGGAA 276 ATTIAAGAAGAACACATATAAAGGATATTTGTCTGAGAGAATATATGGTACCGTGTCACTACCTT A

Fig. 3 A, B. Microsatellite DNA polymorphism in the human glucokinase gene. A The nucleotide sequence of the polymorphic region upstream of exon $1 \mathrm{a}$ is shown. The sequences of the nucleotide primers used to amplify this region are shown in bold-face type.

of the rat glucokinase cDNA sequence by Andreone et al. [14], it became evident that $\lambda$ hGK12-1 encoded part of human glucokinase. Since subsequent reports indicated that the region of glucokinase mRNA present in this clone was common to transcripts expressed by both liver and Beta cells/insulinomas, it was used as a focus to obtain the sequence for the human Beta-cell isoform. The remainder of the human sequence was obtained with a combination of reverse transcription-PCR and RACE-based approaches using human insulinoma RNA. The composite sequence of the human glucokinase cDNA clones is shown in Figure 1 (the strategy for obtaining this sequence is outlined in Materials and methods and in Fig. 1 legend). This sequence indicates that human Beta-cell glucokinase is 465 amino acids $\left(M_{r}=52166\right)$. There is $97 \%$ amino acid identity between human and rat Betacell glucokinase. The fifteen differences between human and rat Beta-cell glucokinase are shown in Figure 1. They are scattered throughout the protein and one is in the region encoded by the Beta-cell specific exon 1 . Six of the differences (amino acids 159, 181, 276, 292, 308, and 342) represent conservative amino acid replacements.

\section{Localization of the human glucokinase gene}

The human glucokinase cDNA probe phGK12-1 hybridized to EcoRI fragments of 11 and $6.1 \mathrm{~kb}$ in digests of human DNA which were readily distinguished from a mouse-specific EcoRI fragment of $18 \mathrm{~kb}$. The presence or absence of the human-specific fragments were scored in a somatic cell hybrid panel comprised of 36 different cell lines. The human specific fragments were only present in those cell lines that retained human chromosome 7 (data not shown) indicating that GCK was on this chromosome. The human GCK gene was also present in two hybrid cell lines with no intact chromosome 7, but with chromosome 7 translocations: hybrid JSRL-17S2 with a $7 / 9$ translocation $[7 \mathrm{pter} \rightarrow 7 \mathrm{q} 22:: 9 \mathrm{p} 24 \rightarrow$ pter]; and XOL-21 [ISO7p: 7 pter $\rightarrow 7$ centromere] localizing the gene to the short arm of chromosome 7 , pter $\rightarrow$ centromere.

The assignment of GCK to chromosome 7 and a more precise regional localization was obtained by in situ hy-

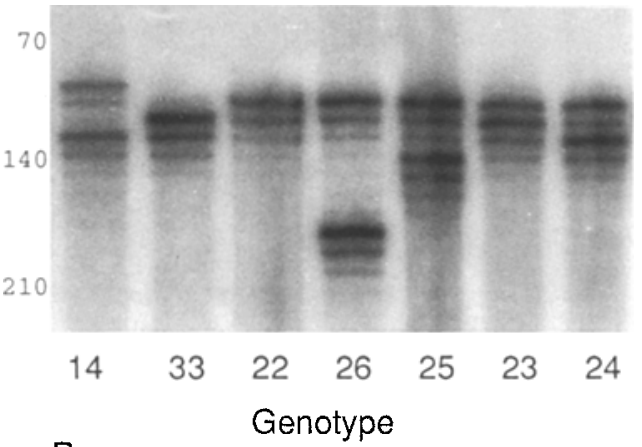

B

B Polymerase chain reaction amplification of microsatelite DNA polymorphism. The genotypes of the unrelated individuals studied here are shown at the bottom of the figure

bridization of ${ }^{3} \mathrm{H}$-labelled phGK12-1 to normal prometaphase chromosomes. The distribution of silver grains over chromosome 7 (Fig. 2) indicated that GCK was in bands $\mathrm{p} 13 \rightarrow \mathrm{p} 14$, with the most likely location being in band $\mathrm{p} 13$.

\section{Characterization of a microsatellite DNA polymorphism}

A region upstream of exon $1 \mathrm{a}$, the Beta-cell-specific exon of human GCK hybridized with a ${ }^{32}$ P-labelled poly (dA$\mathrm{dC})$-poly (dG-dT) probe. The sequence of this region (Fig. $3 \mathrm{~A}$ ) revealed two adjacent regions of repeating dinucleotide repeats; $(\mathrm{TC})_{\mathrm{n}}$ and $(\mathrm{CA})_{\mathrm{n}}$. Oligonucleotide primers flanking this region were selected and used to amplify this region in a series of unrelated subjects. This region was polymorphic (Fig. 3B). Six alleles were noted in a group of 56 unrelated individuals of different races and their frequencies appear to vary among these racial groups (Table 1). This DNA polymorphism showed codominant inheritance in five informative families.

\section{Discussion}

We have determined the sequence of cDNAs encoding the Beta-cell isoform of human glucokinase. Human Beta-cell glucokinase is a protein of 465 amino acids that shares $97 \%$ amino acid identity with the corresponding rat protein. However, in contrast to rat Beta-cell and liver glucokinases which are both comprised of 465 amino acids $[3,4]$, the human Beta-cell and liver isoforms are 465 and 466 amino acids, respectively. This difference in size is a consequence of the differences in the sizes of the segments encoded by the Beta-cell and liver-specific first exons which are 15 and 16 amino acids, respectively. Thus, the sequences of the $\mathrm{NH}_{2}$-terminal domains of the human Beta-cell and liver proteins differ in length and in size. The functional consequences of these differences are unknown.

We have physically mapped the human GCK gene to chromosome 7 in band $\mathrm{p} 13$ and described a microsatellite DNA polymorphism which will be useful for genetic studies. While this manuscript was in preparation, Matsu- 
Table 1. Characterization of microsatellite DNA polymorphism in the human glucokinase gene

\begin{tabular}{|c|c|c|c|c|}
\hline \multicolumn{2}{|c|}{ Allele frequencies } & \multicolumn{3}{|c|}{ Racial group } \\
\hline Ailele & $\begin{array}{l}\text { Size } \\
\text { (base } \\
\text { pairs) }\end{array}$ & $\begin{array}{l}\text { Caucasian } \\
(n=29)\end{array}$ & $\begin{array}{l}\text { Asian } \\
(n=14)\end{array}$ & $\begin{array}{l}\text { African- } \\
\text { American } \\
(n=13)\end{array}$ \\
\hline 1 & 143 & - & - & 0.04 \\
\hline 2 & 141 & 0.32 & 0.25 & 0.46 \\
\hline 3 & 139 & 0.62 & 0.57 & 0.23 \\
\hline 4 & 137 & 0.02 & 0.18 & 0.27 \\
\hline 5 & 135 & 0.02 & - & - \\
\hline 6 & 127 & 0.02 & - & - \\
\hline Heterozygosity & & 0.51 & 0.58 & 0.66 \\
\hline PIC value & & 0.43 & 0.52 & 0.60 \\
\hline
\end{tabular}

PIC, polymorphic information content

tani et al. [15] reported the mapping of human GCK to chromosome $7 \mathrm{p}$ by linkage analysis. Our results are in complete agreement with those of these authors and, in addition, provide a precise physical localization for GCK on the short arm of chromosome 7 within band p13. Matsutani et al. [15] also described a $(\mathrm{CA})_{\mathrm{n}}$ repeat polymorphism in GCK. This microsatellite DNA polymorphism is different from the one that we have reported here. These two microsatellite DNA polymorphisms can be combined to make GCK more informative for linkage studies.

Froguel et al. [16] have recently reported studies showing close linkage of DNA polymorphisms in the glucokinase locus with early-onset Type 2 diabetes. The sequences of human Beta-cell glucokinase mRNA and protein described above will facilitate studies of the role of this candidate diabetes-susceptibility gene in the development of Type 2 diabetes mellitus.

Acknowledgements. This research was supported by the Howard Hughes Medical Institute and NIH Grants DK-20595, GM-20454 and HD-05196. M. Stoffel was supported by a fellowship from the Deutsche Forschungsgemeinschaft. The nucleotide sequences reported in this paper have been deposited in the GenBank data base (accession nos. M86676 and M88011).

\section{References}

1. Magnuson MA (1990) Glucokinase gene structure: functional implications of molecular genetic studies. Diabetes 39:523-527

2. Matschinsky FM (1990) Glucokinase as glucose sensor and metabolic signal generator in pancreatic $\beta$-cells and hepatocytes. Diabetes 39: 647-652
3. Magnuson MA, Andreone TL, Printz RL, Koch S, Granner DK (1989) Rat glucokinase gene: structure and regulation by insulin. Proc Natl Acad Sci USA 86: 4838-4842

4. Magnuson MA, Shelton KD (1989) An alternative promoter in the glucokinase gene is active in the pancreatic $\beta$ cell. J Biol Chem 264: 15936-15942

5. Tanizawa Y, Koranyi LI, Welling CM, Permutt MA (1991) Human liver glucokinase gene: cloning and sequence determination of two alternatively spliced cDNAs. Proc Natl Acad Sci USA 88: 7294-7297

6. Sambrook J, Fritsch EF, Maniatis T (1989) Molecular cloning, a laboratory manual, 2nd Ed, Cold Spring Harbor Laboratory Press Cold Spring Harbor, NY

7. Nishi S, Seino S, Bell GI (1988) Human hexokinase: sequences of amino- and carboxylterminal halves are homologous. Biochem Biophys Res Commun 157: 937-943

8. Fukumoto H, Seino S, Imura H et al. (1988) Sequence, tissue distribution, and chromosomal localization of mRNA encoding a human glucose transporter-like protein. Proc Natl Acad Sci USA 85: 5434-5438

9. Frohman MA, Dush MK, Martin GR (1988) Rapid production of full-length cDNAs from rare transcripts: amplification using a single gene-specific oligonucleotide primer. Proc Natl Acad Sci USA 85: 8998-9002

10. Shows T, Eddy R, Haley L et al. (1984) Interleukin-2 (IL2) is assigned to human chromosome 4. Somatic Cell Mol Genet 10: 315-318

11. Shows TB, Eddy RL, Byers MG et al. (1987) Polymorphic human glucose transporter gene (GLUT) is on chromosome $1 \mathrm{p} 31.3 \rightarrow$ p35. Diabetes 36: 546-549

12. Nakai H, Byers MG, Shows TB, Taggart RT (1986) Assignment of the pepsinogen gene complex (PGA) to human chromosome region 11q13 by in situ hybridization. Cytogenet Cell Genet 43: 215-217

13. Litt M, Luty JA (1989) A hypervariable microsatellite revealed by in vitro amplification of a dinucleotide repeat within the cardiac actin gene. Am J Hum Genet 44:397-401

14. Andreone TL, Printz RL, Pilkis SJ, Magnuson MA, Granner DK (1989) The amino acid sequence of rat liver glucokinase deduced from cloned cDNA. J Biol Chem 264:363-369

15. Matsutani A, Janssen R, Donis-Keller H, Permutt MA (1992) Polymorphic (CA $)_{n}$ repeat element maps the human glucokinase gene (GCK) to chromosome 7p. Genomics 12: 319-325

16. Froguel $\mathrm{Ph}$, Vaxillaire M, Sun $\mathrm{F}$ et al. (1992) Close linkage of glucokinase locus on chromosome $7 p$ to early-onset non-insulindependent diabetes mellitus. Nature 356: 162-164

Received: 28 January 1992

and in revised form: 19 March 1992

Dr. G. Bell

Howard Hughes Medical Institute

University of Chicago

5841 S. Maryland Ave., MC1028

Chicago, IL 60637

USA 